Zeszyty Naukowe Szkoły Głównej Gospodarstwa Wiejskiego

Ekonomika i Organizacja Gospodarki Żywnościowej nr 112, 2015: 101-110

Monika Nalewajek

Wydział Ekonomiczny

Uniwersytet Marii Curie-Skłodowskiej w Lublinie

\title{
Czy rozwój e-commerce wymaga zmiany myślenia o opakowaniu produktów?
}

\section{Wstęp}

Opakowanie, przez wiele lat dosyć marginalnie traktowane w literaturze w kontekście marketingowym, przechodzi obecnie etap coraz większego nim zainteresowania - we wszystkich płaszczyznach. Zmiany prawne (m.in. zwiększone wymagania dotyczące ochrony środowiska), jak również troska o dobro konsumenta (zwiększony nacisk w kierunku informowania), wymagania efektywnościowe nakładane na firmy, zmiany stylu i tempa życia konsumentów - to tylko część zagadnień, które wpływają na kwestie towaroznawcze, logistyczne, jak również marketingowe w opakowalnictwie produktów.

Powszechnie uważa się, że opakowanie ma szczególne znaczenie w segmencie FMCG, jednakże firmy z innych branż udowadniają jak wielka rolę może odgrywać opakowanie w procesie wspierania sprzedaży (np. Apple). Siłę oddziaływania opakowania coraz powszechniej wykorzystuje się w przypadku elektroniki (słuchawki), produktów do remontowania wnętrz (np. pędzle), czy chociażby w przypadku leków (rys. 1).

W kanale stacjonarnym opakowanie zwykło się nazywać cichym bądź niemym sprzedawca [Stewart 1995, s. 1-11]. Będąc jednym z identyfikatorów marki [Górska-Warsewicz 2008, s. 8], wielokrotnie w literaturze wskazywano na jego ważną rolę w procesie sprzedaży [Cichoń i Turek 2002, s. 11-12], gdzie jest jednym z narzędzi realizacji biznesowych i marketingowych celów firmy ${ }^{1}$ [Cichoń i Turek 2002, s. 11-12].

\footnotetext{
${ }^{1}$ Opakuj to! Rola designu w projektowaniu opakowań, raport ekspercki, online: http://www.publicon.pl/raport_opakuj_to_12_07.pdf(data dostępu: 24.01.2015).
} 

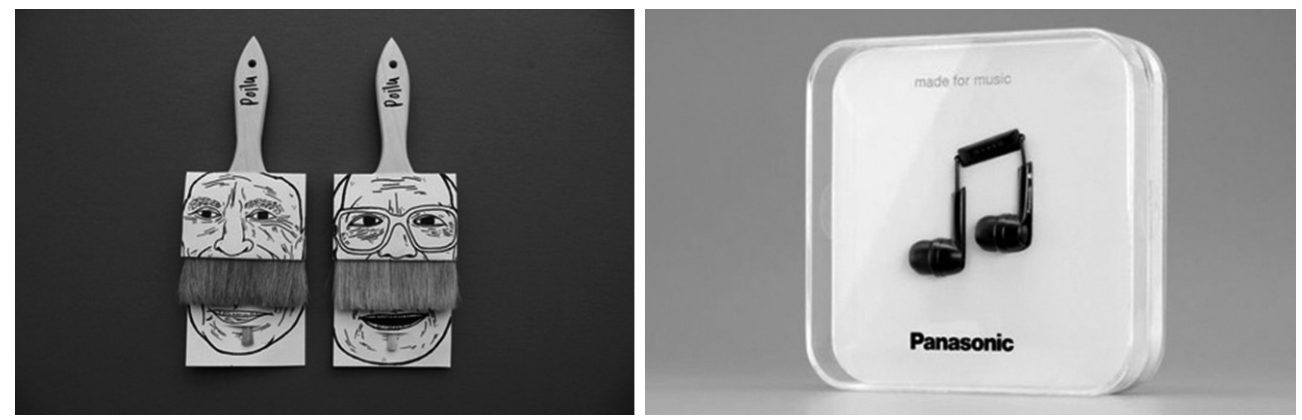

\section{Rysunek 1}

Przykłady kreatywnych opakowań spoza branży FMCG

Źródło: Pinterest.com (data dostępu: 16.01.2015).

Szacuje się, że ponad 70\% decyzji zakupowych podejmowanych jest bezpośrednio w sklepie [Jeżyk 2014, s. 392]. Wraz z intensyfikacją walki o ograniczone miejsce na sklepowych półkach, znaczenie pełnego wykorzystania potencjału opakowania będzie wzrastać ${ }^{2}$. Firma Stora Enso prognozuje zwiększenie znaczenia projektowania opakowania oraz sposobu w jaki wyróżnia się ono na półce sklepowej: „W coraz bardziej konkurencyjnej branży detalicznej, różnicowanie produktu i jego wyróżnienie na półce sklepowej nabierze większego znaczenia. Właściciele marki, jak również sprzedawcy detaliczni jeszcze bardziej intensywnie będą konkurować ze sobą o uwagę konsumentów w punkcie sprzedaży, wykorzystując w tym celu opakowanie. Opakowania wtórne nabiorą większego znaczenia jako nośnik marki, a sprzedawcy detaliczni i właściciele marki będą inwestować coraz więcej w wyższą jakość nadruku na opakowaniu oraz różnicowanie rozwiązań w dziedzinie projektowania ${ }^{3}$.

Atrakcyjne opakowanie pozwala nie tylko odróżnić dwie marki od siebie, ale też komunikuje ich wartość, ułatwiając pozycjonowanie w umyśle konsumenta. Dzięki nietypowemu bądź innowacyjnemu designowi opakowanie może skłonić do zakupu (np. modyfikacja sposobu otwierania/zamykania produktu, limitowana edycja opakowania, zaskakująca forma jaką wykorzystano, by opakować produkt, wyróżniając go na tle produktów danej kategorii, bądź humorystyczne odniesienie się poprzez projekt opakowania do produktu, który zabezpiecza).

\footnotetext{
2 Opakowania detaliczne: rok 2016 i później, stora Enso Packaging Slutions, http:// www,storaensopack.pl/sites/default/files/viewpoint\%20Retail\%20Packaging\%202016\%20and\%20beyond_Polish.pdf, s. 3 (data dostępu: 20.02.2015).

${ }^{3}$ Punkt widzenia Stora Enso na rozwój branży opakowań do żywności - do roku 2016 i dalej, Punkt widzenia Stora Enso 1/2014, s. 2, online: http://www.storaensopack.pl/sites/default/files/ PL_Food.pdf (data dostępu:13.01.2015).
} 
Dodając możliwość interakcji konsumenta z produktem poprzez sklepy samoobsługowe (klient może podnieść, dotknąć, poczuć fakturę, wypróbować sposób działania poprzez tester), gdzie dodatkowo oddziałuje ekspozycja towaru - można zakładać, że wpływ opakowania będzie większy niż na przykład w kanale wirtualnym. Nie mniej jednak są to tylko pewne założenia, gdyż faktycznych badań na ten temat brak. Autorka nie odnalazła naukowych opracowań, które poruszałyby kwestię znaczenia opakowania w przypadku handlu elektronicznego (e-commerce). Stało się to przyczyna, dla której autorka zdecydowała się przeanalizować zmiany w strukturze handlu i zarysować niszę, która w przyszłości stanie się tematem jej badań, a mianowicie kwestię e-opakowania.

\section{Rozwój handlu elektronicznego w Polsce}

Już w 2011 roku wskazywano, iż obecność w internecie będzie dla firm koniecznością, a nie sposobem wyróżnienia się na rynku ${ }^{4}$. Obecnie Polacy coraz chętniej kupują online, a internet ma coraz większy wpływ na to, co, a przede wszystkim gdzie i za ile kupują ${ }^{5}$. Polska przoduje w Europie jeśli chodzi o dynamikę rozwoju e-handlu ${ }^{6}$. Według badań CBOS, już średnio co drugi mieszkaniec Polski robi zakupy w internecie (w 2008 roku ok. 25\%) ${ }^{7}$. Według szacunków w 2015 roku wartość polskiego e-handlu wyniesie 4,3\% polskiego PKB, czyli ponad 38 mld złotych.

Raport Deloitte pokazuje, że do końca 2015 roku 83\% stron internetowych będzie przeglądanych na tabletach i smartfonach, a $65 \%$ populacji na świecie będzie korzystało $\mathrm{z}$ telefonów komórkowych ${ }^{8}$. W związku z tym handel detaliczny musi stać się szybszy, bardziej mobilny i innowacyjny. Deloitte szacuje także, że do 2018 roku globalna sprzedaż za pośrednictwem urządzeń mobilnych przekro-

\footnotetext{
${ }^{4}$ Aktualne wyzwania dla handlu detalicznego czyli jak skutecznie wprowadzić elektroniczny kanat sprzedaży w tradycyjnym sklepie?, PwC 2011, s. 4. http://www.pwc.pl/pl_PL/pl/publikacje/ e_commerce_raport_pwc_pdf (data dostępu: 17.01.2015).

${ }^{5}$ Konsument polski a zakupy w internecie, Nielsen 2012, online: http://www.nielsen.com/pl/pl/insights/reports/2013/konsument-polski-a-zakupy-w-internecie.html (data dostępu:13.01.2015).

6 P. Prajsnar, W e-handlu cena nie gra (glównej) roli, luty 2015, http://www.marketing-news. $\mathrm{pl} /$ theme.php? art $=1929 \& \mathrm{f}=896 \& u t m \_$source $=$FreshMail\&utm_medium=email\&utm_campaign=fm_150206-newsletter (data dostępu: 06.02.2015).

${ }^{7}$ Internauci 2014, Komunikat z badań BOS nr 82/2014, s. 3, http://www.cbos.pl/SPISKOM. POL/2014/K_082_14.PDF (data dostępu: 18:01.2015).

${ }^{8} 2015$ Global Powers of Retailing, Deloitte, online: http://www2.deloitte.com/global/en/pages/ consumer-business/articles/global-powers-of-retailing.html (data dostępu: 2.02.2015).
} 
czy 638 mld dolarów, czyli tyle, ile jeszcze rok temu wynosiła wartość całego handlu elektronicznego na świecie ${ }^{9}$.

Rok 2015 jest też prognozowany, jako punkt zwrotny w sprzedaży elektronicznej za pośrednictwem aplikacji mobilnych ${ }^{10}$. Na świecie urządzenia mobilne odpowiadają obecnie za ponad $30 \%$ wszystkich transakcji internetowych. Szacuje się, że dla branży detalicznej i travel w tym roku ich wartość może osiagnąć 50\%. W Europie liderem w sprzedaży m-commerce jest Wielka Brytania, gdzie mobilną wersję swojej strony internetowej posiada $86 \%$ sprzedawców. W Polsce te wskaźniki są jeszcze o wiele niższe. Głównie dlatego, że ponad połowa polskich sklepów nie oferuje zakupów mobilnych. Nie mniej jednak polscy sprzedawcy, choć wolniej, również wkraczają w etap, w którym sprzedaż za pośrednictwem aplikacji mobilnych zacznie wyprzedzać tradycyjne formy zakupów. Zmiana następuje także po stronie klientów. $63 \%$ osób oczekuje, że w ciągu kilku najbliższych lat będzie robić więcej zakupów z wykorzystaniem urządzenia mobilnego (34\% uważa, że ich nawyki w tej kwestii pozostaną bez zmian $)^{11}$. Obecnie zakupy poprzez smartfony oraz tablety chętniej realizują mężczyźni (rys. 2).

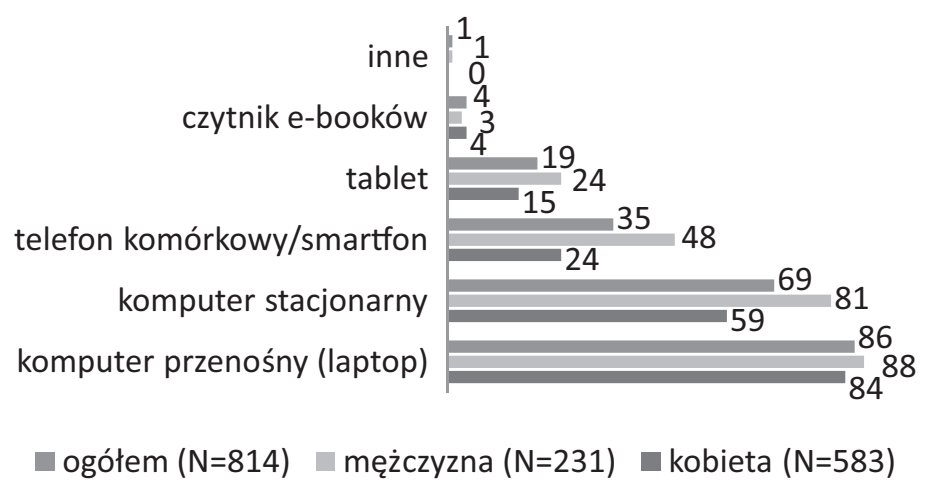

\section{Rysunek 2}

Urządzenia wykorzystywane do e-zakupów (dane w \%)

Źródło: E-commerce w Polsce 2014, Gemius dla e-Commerce Polska, s. 147, dostępne online po zalogowaniu: http://www.ecommercepolska.pl/pl/dla-czlonkow/baza-wiedzydo-rozwoju-biznesu-online/badania-i-raporty/ (data dostępu: 27.01.2015); N = 814, osoby robiące zakupy online.

\footnotetext{
${ }^{9}$ Wyniki raportu ,, 2015 Global Powers of Retailing” Deloitte, online: http://www.marketing-news. $\mathrm{pl} /$ message.php?art=44092\&utm_source=FreshMail\&utm_medium $=$ email\&utm_campaign=fm_ 150211-newsletter (data dostępu: 10.02.2015).

${ }^{10}$ TMT Predictions 2015, Deloitte, online: http://www2.deloitte.com/pl/pl/pages/technology-media-and-telecommunications/articles/tmt-predictions-2015.html (data dostępu: 12.02.2015).

${ }^{11}$ Zwyczaje zakupowe konsumenta digitalnego, ShoppingShow 2014, s. 8. http://www.shoppingshow.pl/raporty/ShoppingShow_2014_RAPORT_zwyczaje_zakupowe_konsumeta_digitalnego_ q.pdf (data dostępu: 17.02.2015).
} 
Wraz z rozwojem i swoistą popularyzacją e-handlu zwiększają się też oczekiwania konsumentów. Internauci spodziewają się, że strona e-sklepu załaduje się w 2 sekundy ( $47 \%$ badanych $)^{12}$. Po upływie 3 sekund niemal połowa opuści już witrynę tego sklepu. Jedna sekunda opóźnienia w ładowaniu to spadek satysfakcji klienta aż o $16 \%{ }^{13}$. Internauci stają się wzrokowcami, „kupują oczami”, a na ich decyzje coraz większy wpływ mają materiały wizualne, gdzie znaczenie nabierają przejrzystość, estetyka, harmonia i coraz bardziej poszukiwany trend less is more. Oczekują funkcjonalnej wyszukiwarki, przyjaznego interfejsu, przejrzystego podziału na kategorie, ale też obecności zwięzłego opisu oraz wizualizacji produktu (co istotne: nie skopiowanych z internetu, ale autorskich zdjećc) ${ }^{14}$.

Poprzeczka dla właścicieli sklepów w kanale wirtualnym jest ustawiona bardzo wysoko. Konsument poświęca przeciętnie jedynie 90 sekund na ocenę prezentowanego na witrynie e-sklepu produktu. W trakcie tego czasu zapada decyzja o kupnie lub zrezygnowaniu z zakupu. Według Baymard Institute, 7 na 10 rozpoczętych transakcji w e-sklepach nie dochodzi do skutku ${ }^{15}$. Internauci są wrażliwi m.in. na dodatkowe opłaty manipulacyjne, konieczność rejestracji (na koniec zakupów), niejasne warunki dostawy, lub, gdy sam proces trwa bardzo długo, a w trakcie niego istnieje konieczność wpisywania bardzo dużej ilości danych.

W świadomości Polaków niekwestionowanym liderem w e-handlu jest Allegro (76\% spontanicznej znajomości marki): „Ten serwis aukcyjny króluje nie tylko w ogólnej kategorii miejsc, w których można dokonać zakupów przez internet, ale też $\mathrm{w}$ wielu poszczególnych grupach produktowych. Poza nim znaczący udział mają często sklepy online'owe marek obecnych w handlu tradycyjnym"16.

\section{E-commerce a rynek FMCG w Polsce}

W korzystaniu z internetu pod kątem zakupów spożywczych zwyczaje Polaków nie różnią się od zwyczajów przeciętnego Europejczyka - dla około 50\% konsumentów to przede wszystkim źródło informacji o produktach ${ }^{17}$. Najczęściej poszukiwane są informacje o cenie, opinie o produkcie, a także aktualne wiadomości o promocjach i okazjach. Na tle Europy Polacy są dużo bardziej wrażliwi

\footnotetext{
${ }^{12}$ Kissmetric, infografika przygotowana przez Gomez.com, Akamai.com, http://blog.kissmetrics. com/wp-content/uploads/2011/04/loading-time.pdf (data dostępu: 20.02.2015).

13 Tamże.

${ }^{14}$ P. Prajsnar, W e-handlu..., op. cit.

${ }^{15}$ E-Commerce Checkout Usability, online: http://baymard.com/checkout-usability (data dostępu: 7.02.2015).

${ }^{16}$ E-commerce w Polsce $2014 \ldots$, op. cit.

${ }^{17}$ Konsument polski a zakupy $w$ internecie..., op. cit.
} 
na wahania cenowe. Stają się też coraz bardziej świadomymi konsumentami, którzy czytają informacje na opakowaniu dotyczących produktu, bardziej niż przeciętny Europejczyk przejmują się wpływem jedzenia na zdrowie i pod tym kątem modyfikują listę zakupów. Rzadziej jednak niż przeciętny Europejczyk dokonują przez internet zakupów spożywczych (szczególnie dużo kupują natomiast biżuterii, ubrań oraz sprzętu elektronicznego).

Sprzedaż żywności przez internet w większości krajów Europy sięga zaledwie kilku procent. Szacuje się, że za 10 lat w Wielkiej Brytanii, która jest europejskim liderem internetowej sprzedaży żywności, udział tej formy zakupów wzrośnie do $20 \%^{18}$.

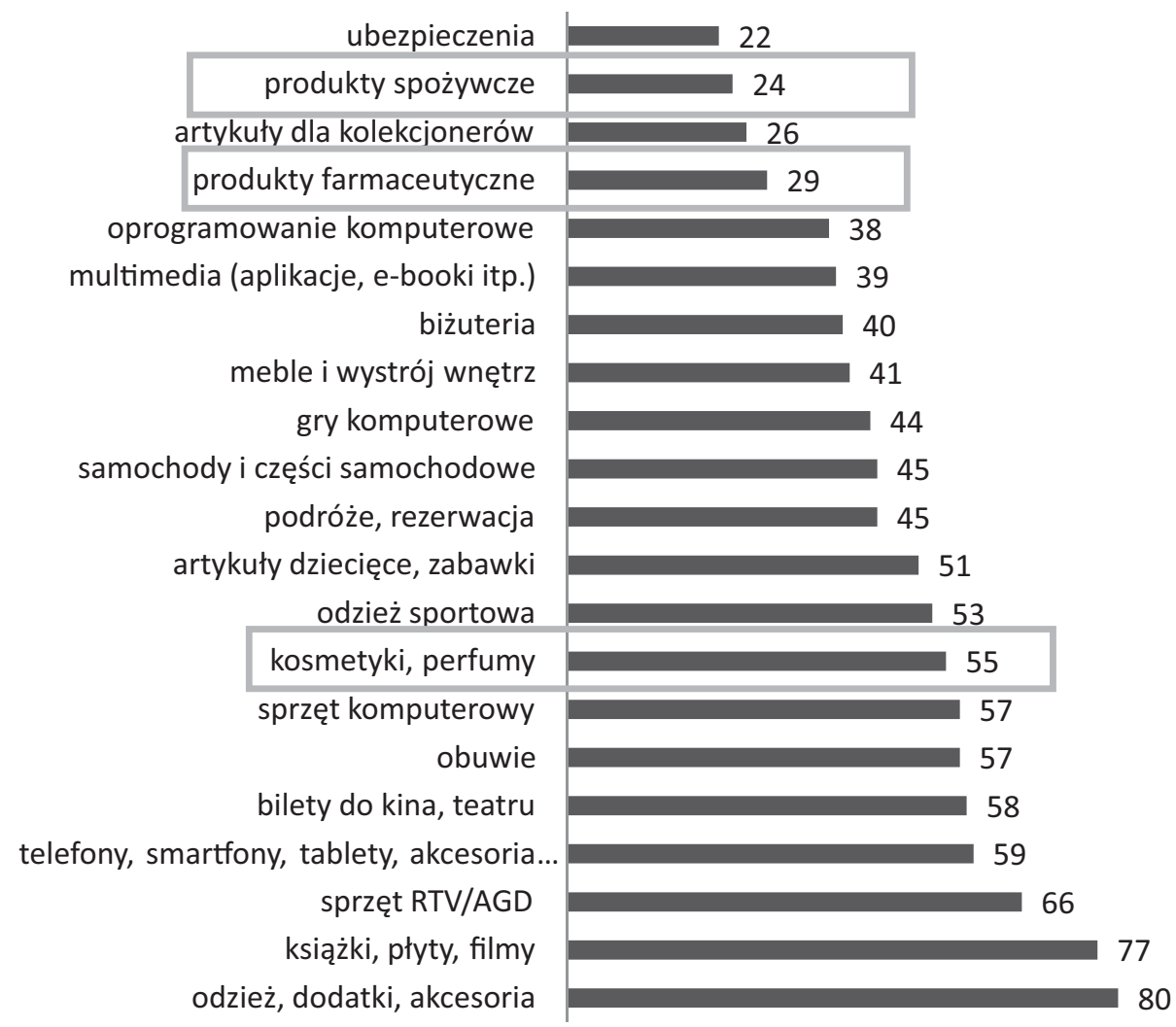

\section{Rysunek 3}

Produkty kupione choć raz przez internet [\%]

Uwaga: obramowaniem zaznaczono produkty z kategorii FMCG.

Źródło: E-commerce w Polsce 2014..., op. cit., s. 79; N = 814, osoby robiące zakupy online.

\footnotetext{
${ }^{18}$ Opakowania detaliczne: rok 2016 i później, Stora Enso Packaging Solutions, http://www.storaensopack.pl/sites/default/files/Viewpoint\%20Retail\%20Packaging\%202016\%20and\%20beyond_Polish.pdf, s. 6 (data dostępu: 18.02.2015).
} 
Badanie „E-commerce w Polsce 2014”"19 wykazało, że artykułów spożywczych respondenci poszukiwaliby w Alma24.pl (17\%), Etesco.pl (16\%) oraz Allegro.pl (10\%). W przypadku aptek internetowych mieli wyraźne problemy ze wskazaniem jakiejkolwiek marki (86\% odpowiedziało „,nie wiem”). Najpopularniejszy Doz.pl uzyskał wynik jedynie 6\% znajomości. Perfumerie oraz drogerie internetowe w świadomości polskich konsumentów to przede wszystkim Sephora.pl (10\%), Rossmann.com.pl (9\%) oraz Douglas.pl (8\%), a więc marki znane głównie z kanału fizycznego. Marka stricte internetowa (Iperfumy.pl) uzyskała jedynie $3 \%$ wskazań (rys. 3).

Co ciekawe, najwięcej (35\%) produktów spożywczych przez internet kupują osoby w wieku powyżej 50 lat, najmniej zaś (13\%) konsumenci w wieku 19-24 lata. Podobnie z produktami farmaceutycznymi - najchętniej przez kanał wirtualny kupują je osoby w wieku 35-49 oraz te powyżej 50. roku życia (45\%), a najrzadziej osoby w wieku 19-24 lat (7\%).

\section{Koncepcja e-opakowania}

W kontekście wszystkich przytoczonych informacji warto zastanowić się nad znaczeniem opakowania w handlu elektronicznym. Zebrane przez autorkę dane wskazują na szybki wzrost branży e-commerce (w tym m-commerce), który dokona się w ciągu najbliższych 2-3 lat. Dodając do tego kwestie zmiany zachowań i oczekiwań konsumentów, może okazać się, że funkcja opakowań będzie musiała ulec pewnym (jeśli nie znacznym) modyfikacjom: „Dotychczas największym nowatorstwem wykazywały się segmenty niezwiązane z żywnością. Jednak wraz z dojrzewaniem tego kanału sprzedaży coraz więcej konsumentów oczekuje rekompensaty za typowe doświadczenia, których brakuje podczas zakupów przez internet"20.

Należy zauważyć, że opakowanie w kanale wirtualnym nie jest do końca tym samym, co w kanale stacjonarnym. Za e-opakowanie należy uznać pewną reprezentację opakowania w postaci wizualizacji produktu (zdjęcia, wideo, wizualizacja $360^{\circ}$ ) oraz opisów (skład, data ważności, dodatkowe informacje), które często są rozdzielone (materiały graficzne są stosunkowo małe i trudno byłoby odczytać wszystkie informacje bez ich „powiększenia” i wyszczególnienia w opisie produktu). Dodatkowo oferowane rozwiązania technologiczne pozwalają na wykorzystywanie rozszerzonej rzeczywistości w kreowaniu doświadczeń związanych z opakowaniem (np. aplikacja Blip, dzięki której po najechaniu

\footnotetext{
${ }^{19}$ E-commerce w Polsce $2014 \ldots$, op. cit.

${ }^{20}$ Opakowania detaliczne: rok 2016 i później..., op. cit., s. 6.
} 
kamerą ze smarfona na produkt wyświetla się książka kucharska dostosowana kształtem do kształtu produktu, pokazująca możliwe kulinarne zastosowania skanowanego produktu). Poprzez e-opakowanie należy rozumieć więc cyfrową wersję opakowania produktu wykorzystywanego w e-commerce ${ }^{21}$ (rys. 4).

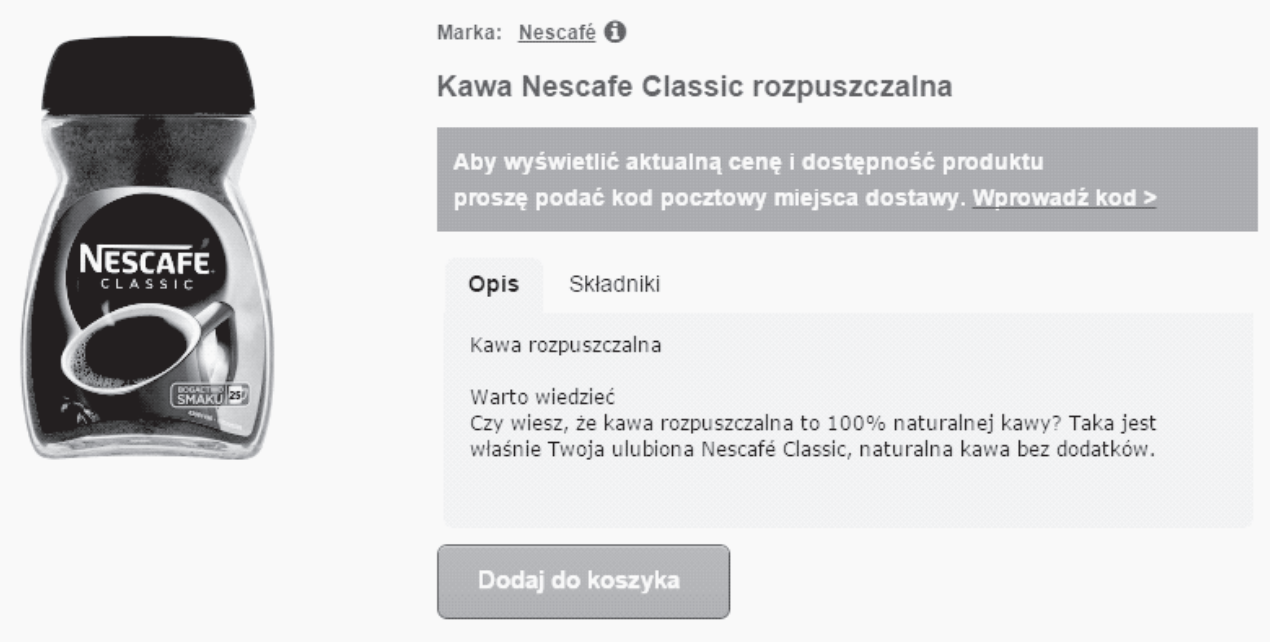

Rysunek 4

Przykład e-opakowania

Źródło: http://alma24.pl/produkt/23719247/kawa-nescafe-classic-rozpuszczalna (data dostępu: 23.02.2015).

\section{Podsumowanie}

Zmiany w handlu oraz zmiany zachowań konsumenckich (e-konsument, Jaciow i Wolny 2011, s. 10) wymuszają zweryfikowanie, jak zmienia się rola opakowania w handlu elektronicznym. W obliczu zarysowanych $w$ artykule tendencji, temat e-opakowania wydaje się niezwykle aktualny, interesujący oraz wymagający przeprowadzenia badań. Ich wyniki mogłyby dać odpowiedź na pytania dotyczące m.in. wpływu opakowania na decyzje zakupowe w e-handlu, oddziaływania na emocje konsumenta, postrzeganie marki (prowadzenie spójnej strategii komunikacji wymaga dostosowania działań do obydwu kanałów zakupowych, chociażby

${ }^{21}$ Za autora pojęcia e-opakowanie należy uznać Bartosza Kiełbińskiego (eStoreMedia.com), definicja zaczerpnięta za: http://konferencje.rp.pl/wydarzenie/prelegents/2194,obecne-vs-nowewymogi-w-zakresie-znakowania-zywnosci-w-tym-sprzedazy-internetowej.html (data dostępu: 17.01.2015). 
bieżąca aktualizacja opakowań w segmencie FMCG wydaje się zadaniem czasochłonnym i żmudnym). Uzyskane wyniki mogłyby być pomocne w decyzjach dotyczących kreacji opakowań i działań marki w zakresie e-commerce.

\section{Literatura}

Aktualne wyzwania dla handlu detalicznego czyli jak skutecznie wprowadzić elektroniczny kanat sprzedaży w tradycyjnym sklepie?, PwC 2011, s. 4, http://www.pwc.pl/pl_PL/pl/ publikacje/e_commerce_raport_pwc_pdf.

CICHOŃ M., TUREK P., 2002: Opakowanie jako narzędzie reklamy i sprzedaży, Zeszyty Naukowe Akademii Ekonomicznej w Krakowie 595, s. 11-12, 2015.

Global Powers of Retailing, Deloitte, http://www2.deloitte.com/global/en/pages/consumerbusiness/articles/global-powers-of-retailing.html.

E-Commerce Checkout Usability, http://baymard.com/checkout-usability.

E-commerce w Polsce 2014, Gemius dla e-Commerce Polska, dostępne online po zalogowaniu: http://www.ecommercepolska.pl/pl/dla-czlonkow/baza-wiedzy-do-rozwoju-biznesu-online/badania-i-raporty/.

GÓRSKA-WARSEWICZ H., Perspektywy rozwoju marek $w$ sektorze żywnościowym $w$ Polsce, Zeszyty Naukowe SGGW w Warszawie - Problemy Rolnictwa Światowego, t. 5 (20), s. 8.

JACIOW M., WOLNY R., Polski e-konsument. Typologia, zachowania, Helion 2011, s. 10.

JEŻYK E., 2014: Design opakowania i jego elementy w procesie podejmowania decyzji zakupowych, Marketing i Rynek 2014, nr 4 (CD), s. 392.

Kissmetric, Gomez.com, Akamai.com, http://blog.kissmetrics.com/wp-content/uploads/2011/04/loading-time.pdf.

Komunikat z badań BOS, Internauci 2014, nr 82/2014, s. 3, http://www.cbos.pl/SPISKOM. POL/2014/K_082_14.PDF.

Konsument polski a zakupy w internecie, Nielsen 2012, http://www.nielsen.com/pl/pl/insights/reports/2013/konsument-polski-a-zakupy-w-internecie.html.

Opakowania detaliczne: rok 2016 i później, Stora Enso Packaging Solutions, http://www.storaensopack.pl/sites/default/files/Viewpoint\%20Retail\%20Packaging\%202016\%20and\%20beyond_Polish.pdf, s. 3.

Opakuj to! Rola designu w projektowaniu opakowań, raport ekspercki, http://www.publicon. pl/raport_opakuj_to_12_07.pdf.

PRAJSNAR P., W e-handlu cena nie gra (głównej) roli, luty 2015, http://www.marketingnews.pl/theme.php?art $=1929 \& \mathrm{f}=896 \&$ utm_source=FreshMail\&utm_medium=email\&utm_campaign=fm_150206-newsletter.

Punkt widzenia Stora Enso na rozwój branży opakowań do żywności - do roku 2016 i dalej, Punkt widzenia Stora Enso 1/2014, s. 2, online: http://www.storaensopack.pl/sites/default/files/PL_Food.pdf.

STEWART B., Packaging as an effective marketing tool, Kogan Page-pira, 1995, s. 1-11.

TMT Predictions 2015, Deloitte, online: http://www2.deloitte.com/pl/pl/pages/technologymedia-and-telecommunications/articles/tmt-predictions-2015.html.

Wyniki raportu „2015 Global Powers of Retailing” Deloitte, online: http://www. marketing-news.pl/message.php?art $=44092 \& u t m \_s o u r c e=$ FreshMail\&utm medium=email\&utm_campaign=fm_150211-newsletter. 
Zwyczaje zakupowe konsumenta digitalnego, ShoppingShow 2014, http://www.shoppingshow.pl/raporty/ShoppingShow_2014_RAPORT_zwyczaje_zakupowe_konsumeta_digitalnego_q.pdf.

\section{Abstrakt}

W artykule zweryfikowano i przedstawiono zmiany w handlu, jakie dokonują się w ciągu ostatnich kilku lat. Zaprezentowano także kierunki tendencji rozwojowych, których w ciagu 2-3 lat prawdopodobnie będziemy świadkami. Zebrane dane pokazują na znaczący rozwój e-handlu, a także na rosnące zainteresowanie związane z zakupami online w segmencie produktów FMCG (również przez tablety i smartfony). Zmiany te skłaniają do zastanowienia się, jakie konsekwencje dla znanych już naukowcom i badaczom relacji między opakowaniem a decyzjami zakupowymi będzie miał dalszy rozwój handlu internetowego.

Autorka zaprezentowała koncepcję e-opakowania, która to jak dotychczas nie została wykorzystana $\mathrm{w}$ nurcie naukowym i, będąc stosunkowo nową, nie doczekała się jeszcze badań naukowych, które z pewnością warto by było przeprowadzić.

Słowa kluczowe: e-opakowanie, e-handel, handel elektroniczny, opakowanie

\section{Does e-commerce require changing approach toward packaging?}

\section{Abstract}

This paper presents changes in trade which have been taking place over the past few years. The author presented directions of development that we will probably experience within 2-3 years. The data shows significant development of e-commerce, as well as growing interest in online purchasing in the segment of FMCG products (also via tablets and smartphones). These changes induce to think what will be the consequences of further development of e-commerce for already well-known relationships between product packaging and consumers' purchasing decisions.

The author presented the concept of e-packaging, which has not been used so far in the scientific mainstream. Since it is a relatively new issue, it has not been explored yet. Nevertheless, it is certainly worth to carry out research on.

Key words: e-package, e-commerce, package 